\title{
Vazamentos como acontecimento jornalístico: notas sobre performatividade mediática de atores sociais
}

\section{Leaks as a journalistic event: notes on the mediatic performativity of social actors}

Carlos Alberto Carvalho

Programa de Pós-Graduação em Comunicação Social da Universidade Federal de Minas Gerais (PPGCOM-UFMG)،

Belo Horizonte, MG, Brasil.

ORCID: 0000-0001-8433-8794

<carloscarvalho0209@gmail.com>

\author{
Mozahir Salomão Bruck \\ Programa de Pós-Graduação em Comunicação Social da \\ Pontifícia Universidade Católica de Minas Gerais (PPGCOM- \\ PUC Minas), Belo Horizonte, MG, Brasil. \\ Orcid: 0000-0002-9983-6072 \\ <mozahir@uol.com.br>
}

\section{Como citar este artigo (How to cite this article):}

CARVALHO, Carlos A.; BRUCK, Mohazir S. Vazamentos como acontecimento jornalístico: notas sobre performatividade mediática de atores sociais. Revista Famecos, Porto Alegre, v. 25, n. 3, p. 1-20, setembro, outubro, novembro e dezembro de 2018: ID29713. DOI: http://dx.doi.org/10.15448/1980-3729.2018.3.29713.

\section{RESUMO}

Referenciados na interceptação e divulgação de conversa telefônica mantida entre a presidenta Dilma Rousseff e o ex-presidente Lula, discutimos neste artigo a performatividade do acontecimento jornalístico, sob a forma dos vazamentos intencionais para os media. Em que medida, segundo proposição de Pierre Nora, modifica-se o estatuto ontológico e teórico do acontecimento, quando este não mais poderia existir sem a presença dos media, torna-se uma das questões centrais aqui discutidas. A aliança entre os media, setores do judiciário, do Ministério Público e da Polícia Federal são ainda considerados vitais para esclarecer as tentativas de deter os transbordamentos de sentidos e os impactos dos vazamentos tornados acontecimentos, o que é parte do que entendemos como performatividades envolvidas em jogos de poder a que está sujeito qualquer acontecimento.

\begin{abstract}
Based on the interception and disclosure of a telephone conversation between President Dilma Rousseff and former President Lula da Silva, we discuss the performativity of the journalistic event, in the form of intentional media leaks. To what extent - according to Pierre Nora's proposition - the ontological and theoretical status of an event can change, as it no longer exists without the presence of media; that is one of the central issues discussed here. The alliance between the media, the judiciary, the Public Prosecutor's Office and the Federal Police are still considered vital to clarify the attempts to stop the overflow of meanings and impact of leaks that have become events - which is part of what we understand as power play performativities, to which any event is subject.
\end{abstract}

Keywords: Event. Leaks. Journalism

\section{Acontecimento e mídia}

Em conhecido artigo, Adriano Duarte Rodrigues (1993, p. 27) propõe que acontecimento é "tudo aquilo que irrompe na superfície lisa da história de entre uma multiplicidade aleatória de factos virtuais". Para além da problemática ideia de que a história constituiria uma superfície lisa, e não o conjunto, no mínimo 
contraditório e conflituoso, de ações humanas e naturais cujos significados são objeto permanente de disputas de sentido e jogos de poder, a noção de acontecimento de Adriano Duarte partilha o entendimento de que, aplicada ao jornalismo, teríamos como resultado que para obter valor como notícia, todo acontecimento teria que ser de rara ocorrência. Inscrito na lógica do estatisticamente pouco provável, o acontecimento adquiriria relevância informativa diretamente proporcional à sua inesperada ocorrência.

O que define um acontecimento como notícia, no entanto, não parece ser assim tão facilmente solucionável, a começar pela razão mais aparente de que transtornos naturais, como furacões, enchentes, dentre outros, além de acontecimentos sociais, como atentados, corrupções políticas, abalos econômicos, somados a uma lista ao infinito de outros eventos, apesar de recorrentes - e portanto abundantes e estatisticamente repetidos - frequentarem cotidianamente os noticiários dos mais diversos media jornalísticos. O que define um acontecimento como noticiável, consequentemente, é uma rede mais complexa de fatores que se enraízam em relações sociais, em métodos próprios de organização das redações jornalísticas, com seus rituais de produção e critérios editoriais (Tuchman, 1978), em motivações políticas, econômicas e ideológicas nem sempre perceptíveis na superfície ou confessáveis com honestidade. Dos apontamentos de Adriano Duarte sobre o acontecimento, também exploraremos, adiante, a noção dos meta-acontecimentos, cuja ideia de performatividade é esclarecedora acerca das questões sobre as quais mais diretamente nos detemos neste artigo.

Não nos move nas reflexões aqui propostas, no entanto, um inventário de critérios que tornariam um acontecimento noticiável, assim como não estamos à procura de uma tipologia que acrescentasse à já extensa taxonomia dos acontecimentos mais uma categoria. Objetivamos tomar os vazamentos de conversas telefônicas interceptadas, legalmente ou não, de depoimentos prestados a membros do Ministério Público e da Polícia Federal, supostamente sob condição de sigilo legalmente necessário segundo pressupostos do bom andamento das investigações e da preservação da reputação das pessoas investigadas, como o mote para a compreensão de como tais vazamentos de gravações telefônicas, para parte da imprensa, podem constituir, por si só, acontecimentos cujos objetivos pareceram indicar claras interferências na vida política brasileira recente.

Tomamos como corpus para análise um conjunto de textualidades jornalísticas que noticiaram vazamentos, principalmente no período do controverso processo de impeachment da presidenta Dilma Rousseff. Destacase neste artigo o episódio ocorrido em 16 de março de 2016, quando a Polícia 
Federal, depois de autorização do juiz Sergio Moro, divulgou para a imprensa conversas telefônicas do ex-presidente Luiz Inácio Lula da Silva, sendo a última delas com a então presidenta Dilma Rousseff.

Interessa-nos, como gesto analítico, identificar como os vazamentos constituíram uma modalidade de prática jornalística que se distancia de princípios tidos como desejáveis ética e legalmente por parte da imprensa. Mas também, na linha das proposições de Pierre Nora, para quem modernamente "não há acontecimento sem os media" (Nora, 1984, p. 47), refletir sobre o que significa, para a constituição, difusão e interpretação/reinterpretação do acontecimento, o seu apanhar jornalístico e, ao menos no caso brasileiro que nos motiva, os sentidos das formas de tornar vazamentos acontecimentos públicos e jornalísticos com potencial de alterar os rumos políticos de uma nação. Como acontecimentos que dão a impressão de procedimentos sofisticadamente controlados segundo objetivos políticos a alcançar, os vazamentos/divulgações dão ainda a ver alianças entre partes do Ministério Público, da Polícia Federal e de juízes com setores da imprensa. Essa forma de aliança coloca em xeque, simultaneamente, princípios desejáveis de ação impessoal, de equilíbrio, de preservação de intimidades e reputações e de ação segundo preceitos éticos e legais que idealmente devem reger ações de todos os atores sociais listados. É a vida político-institucional do País, incluindo-se os media, em arranjos paralelos e cuja orquestração evidencia objetivos que transcendem a natureza e o próprio sentido de sua existência na sociedade.

Pensar os acontecimentos nessa chave implica situá-los, nos termos de Paul Ricoeur (1994), na dialética agir-sofrer o acontecimento, assim como reconhecer que, uma vez produzido ou eclodido, um acontecimento não pode mais ser controlado por um único agente, ou mesmo por um vasto conjunto deles. Consequentemente, situar a proposição de Nora sobre a relação íntima entre mídia e acontecimento como parte de uma preocupação teórica e metodológica com o ofício historiográfico, e não como a construção unilateral do acontecimento pelo jornalismo, é vital. Nesse sentido, são necessárias as considerações do próprio autor:

Com efeito, temos toda a sensação de viver no meio de falsos acontecimentos. Diante de quase tudo o que em uníssono fazem os jornais, tem-se a impressão de que todo esse ruído artificial da actualidade não faz mais do que mascarar alguma coisa, uma história que avança ao passo pesado e lento das legiões romanas. Parece-me que não existe o pseudo-acontecimento. É o próprio acontecimento que, em relação à História tradicional, mudou de natureza por causa da transformação operada pelos mass-media. Vivemos doravante um 
sistema de inflação fenomenológica como num sistema de inflação monetária (Nora, 1984, p. 46).

As proposições de Pierre Nora apontam simultaneamente para duas ordens teóricas e metodológicas implicadas na avaliação dos acontecimentos em suas formas contemporâneas de existência concomitante à explosão dos mais variados media: uma ordem implica o fazer historiográfico, relativamente ao qual Nora está filiado; o outro diz dos modos de compreensão dos media, particularmente os jornalísticos. Relativamente ao acontecimento, ele não pode mais ser compreendido somente pela lógica indicada por Paul Ricoeur (1994, p. 139), segundo a qual, "no sentido ontológico, entende-se por acontecimento histórico o que se produziu efetivamente no passado". Os acontecimentos na perspectiva de Pierre Nora estão, doravante, inscritos na ordem das urgências pressupostas como típicas da factualidade, são movidos por algo como uma espécie de "aceleração da história", implicando novas dinâmicas na dialética relação entre memória e história. Nas palavras do autor:

Ainda mais: é o modo mesmo da percepção histórica que, com a ajuda da mídia, dilatou-se prodigiosamente, substituindo uma memória voltada para a herança de sua própria intimidade pela película efêmera da atualidade (Nora, 1993, p. 8).

Para o historiador, está posto o desafio de compreender o acontecimento, e por extensão a própria noção de história, a partir de premissas não mais exclusivamente voltadas para a história como a possibilidade de compreensão do passado e, a partir dele, iluminar o presente e, no limite, lançar indagações sobre como será o futuro. Nora aponta uma tensão em termos do trabalho de dois importantes atores sociais: o historiador e o jornalista. $\mathrm{O}$ acontecimento não dependeria mais, segundo Nora, da validação do historiador para assim ser considerado, a partir daquilo que ele havia promovido de mudanças na ordem das coisas. Por sua vez, para o jornalista, mais provavelmente, fica a sensação às vezes arrogante e pretensiosa de "estar fazendo a história", e não mais simplesmente a presenciando, ou testemunhando. Mais uma vez é esclarecedor recorrer a Pierre Nora:

No acontecimento de tipo moderno, pelo contrário, já não é o historiador que dispõe, nem mesmo o jornalista, que não é mais que o eco instantâneo duma coisa muito mais vasta, e que forma esse emaranhado da actualidade que muda completamente o nosso vivido histórico e que constitui a sua natureza. É o acontecimento que faz o historiador (Nora, 1984, p. 48). 
Como nosso foco recai sobre os modos como certos acontecimentos se encontram umbilicalmente ligados às lógicas dos media, tomamos os desafios teóricos e metodológicos implicados nas ações de historiadores e jornalistas envolvidos nessa dinâmica somente naquilo que é essencial para pensarmos os vazamentos como acontecimentos estrategicamente construídos por agentes fora do circuito produtivo dos media noticiosos, mas plenamente conscientes do potencial de difusão de informações como modalidades de pressão e chantagem jurídica, policial e política. Em outros autores (Mouillaud e Porto, 1997; Vicente, 2009) podem ser consultadas outras dimensões implicadas na equação acontecimento/história/historiadores/jornalistas.

A esse pano de fundo, é necessário acrescentar outro, sintetizado por Maximiliano Martin Vicente (2009, p. 43): "o acontecimento existe em função do relato feito dele". Entendemos, referenciados na dialética ricoeuriana do agir e sofrer o acontecimento, que este se encontra em uma complexa rede de disputas de poder sobre seu real significado e intensas disputas e jogos de atribuição de sentidos que buscam, pela discursividade, atribuir significados aos acontecimentos, deles extraindo efeitos concretos sobre as dinâmicas históricas, culturais, ideológicas, políticas e outras modalidades da vida social.

\section{O discurso feito acontecimento}

Em sua proposição acerca dos meta-acontecimentos, Rodrigues (1993) assinala que esses seriam regidos pelas regras do mundo simbólico, do mundo da enunciação. "São, por isso, acontecimentos discursivos, actualizações de enunciados pertencentes a vários regimes enunciativos que se encadeiam entre si, segundo regras de encadeamento próprias". (Rodrigues, 1993, p. 30). Para o autor, os media, ao darem conta dos atos enunciativos, não apenas Ihe conferem notoriedade pública, "alargando indefinidamente o âmbito e o alcance das transformações que operam no mundo" (Rodrigues,1993, p. 31), mas acabam por realizar novos atos ilocutórios e perlocutórios. Se os atos ilocutórios ${ }^{1}$, na acepção de Rodrigues (1993), parecem ser uma condição inerente ao discurso jornalístico-mediático, os perlocutórios, por sua vez, distinguem-se por se estabelecerem, eles mesmos, como um novo acontecimento que vem impactar o mundo da vida. Como observa Rodrigues:

1 Rodrigues (1993) indica seu entendimento dos atos ilocutórios e perlocutórios a partir de J.L.Austin. llocutórios seriam aqueles atos em que, no caso dos media, quando os veículos, ao relatarem um acontecimento, além do acontecimento relatado, produzem ao mesmo tempo o relato do acontecimento como um novo acontecimento. Já os atos perlocutórios são aqueles que, além de fazerem o que fazem, em sua condição de locução, produzem efeitos pelo fato de dizê-lo. Ou seja, são enunciações performativas que realizam pelo fato de enunciarem. 
Ao darem conta dos actos enunciativos, os media não só lhes conferem notoriedade pública, alargando assim indefinidamente o âmbito e o alcance das transformações que operam no mundo, como realizam igualmente novos atos ilocutórios e perlocutórios de acordo com suas próprias regras enunciativas (Rodrigues, 1993, p. 31).

A proposição teórica de Rodrigues (1993) tem contribuição relevante para a discussão aqui proposta, mas em nosso entendimento se mostra insuficiente em termos da arquitetura nocional necessária para se pensar os vazamentos na imprensa. Em primeiro lugar, porque sobre a matéria prima dos vazamentos - sua textualidade documental ou audiovisual - há sempre suspeição patrocinada tanto pelas condições e circunstâncias de sua obtenção quanto pelas intencionalidades de sua divulgação. Por assim dizer, as variáveis e condicionantes do enunciado são tão ou mais impactantes do que aquilo que foi proferido. Por isso mesmo, para tentar avançarmos um pouco, valemo-nos da ideia de Louis Quéré (2012) sobre a dupla vida do acontecimento.

O ponto de partida da proposição nocional que nos interessa em Quéré (2012) é a ideia de que os acontecimentos não dizem respeito apenas a mudanças existenciais, mas que se transformam em objetos dos quais tomamos consciência, ganhando, consequentemente, novos modos de operação e características novas. "Ele se torna não só um objeto e uma fonte de inferências e raciocínios, mas também um meio de ação controlada" (Quéré, 2012, p. 31). Nessa perspectiva, os acontecimentos são, para o autor - inspirado em Herbert Mead - o que vem a ser, nunca estão dados como algo fixo no mundo. Para que um acontecimento venha a ser entram em operação tanto as ações discursivas, materializadas por atores sociais situados em condições específicas de existência em relações sociais, quanto ações que transcendem as condições mais propriamente discursivas, por exemplo, estratégias para mitigar os efeitos de um acontecimento natural, como um terremoto, ou atitudes em campos políticos, econômicos e outros mais que, tanto visam agir sobre o curso de um determinado acontecimento, quanto podem ainda vir a desencadear outros acontecimentos.

Quando nos voltamos para os vazamentos como acontecimentos deliberadamente produzidos para a produção de interferências institucionais, estamos em um campo que torna ainda mais complexas e problemáticas as características da dupla vida dos acontecimentos. Gravar conversas entre personagens políticas centrais na condução de um governo e divulgá-las deliberadamente, além da obrigatória articulação com setores dos media para que o efeito desejado seja alcançado, aponta para o desejo de interferência e controle dos próprios cursos históricos. E não estamos entendendo estes como possuidores de uma naturalidade independente de atores sociais, pelo 
contrário. O que torna emblemático o caso em tela - a prática dos vazamentos como uma produção frenética de acontecimentos - é que as personagens envolvidas nessas engrenagens produtivas, o Judiciário, o Ministério Público, a Polícia Federal e a própria mídia parecem ter atuado como se o curso dos fatos pudesse ser interrompido/redirecionado e, mais ainda, controlado. Em outros termos, denotou-se, neste episódio, claramente a ilusão de que acontecimentos possam orquestrar-se, prevalentemente, guiados pelo desejo de conduzi-los, o que negaria sua condição de performatividade que, se em Adriano Duarte Rodrigues (1993) parece sugerida como atinente apenas ao nível da produção discursiva, com Louis Quéré (2012) alcança problematização mais abrangente e complexa, posto que discurso e ação, ainda que possam ser faces de uma mesma moeda, não são mutuamente excludentes.

Outras dimensões para a compreensão acerca dos vazamentos como acontecimentos estratégica e deliberadamente produzidos são ainda necessárias, pois tanto as formulações de Rodrigues (1993), quanto as de Quéré (2012), supõem, talvez ingenuamente, que o acontecimento possui vida própria, seja qual for o significado possível de tal noção. Somente no momento em que ocorre (o happening, na consideração pragmatista à qual se filia Quéré (2012) é que o acontecimento seria lançado, na perspectiva de Rodrigues (1993), à performatividade discursiva, situando-o na condição de meta-acontecimento, ou ao escrutínio, ao inquérito, na proposição de Quéré (2012). Os vazamentos, como os detalhes adiante reforçarão, não nascem de "geração espontânea", são, antes, minuciosamente pensados pelos agentes por eles responsáveis, o que requer tempo político e demais condições para que sua repercussão seja a ideal, o que pressupõe, arrogantemente, que não poderão significar nada além do seu "conteúdo" aparentemente óbvio. Mas cabe aqui uma ressalva: não estamos com isso afirmando que tais acontecimentos, por terem tido parto à fórceps, serão inquiridos, discursivizados e interpretados segundo um único ponto de vista: aquele de quem os promoveu. Estão também sujeitos ao vir a ser pragmatista, imersos, a partir do seu vir à luz, nos jogos de poder e nas disputas de sentido.

E é também por isso que ações adicionais se fazem necessárias nessa busca de controle dos transbordamentos de sentido dos vazamentos processo do qual a divulgação para os media é parte essencial. Mas não só. Os vazamentos têm imediata e coordenada repercussão, que envolve ações espetaculares de condução coercitiva pela Polícia Federal, que a partir de ordens emitidas por juízes comprometidos com os mesmos objetivos, e validados por setores do Ministério Público, impactam decisivamente a imagem pública de pessoas suspeitas que, em grande parte das situações, não haviam sequer sido intimadas a comparecer perante a Justiça. Portanto, a priori, não poderiam ser 
conduzidas coercitivamente, instrumento legal cuja aplicação somente pode ocorrer diante de recusa de atender a intimação. Em síntese, os vazamentos são formas contemporâneas de acontecimentos, considerando-se as proposições de Pierre Nora (1984), mas certamente com um grau de distinção daqueles de que se ocupou o historiador.

Cabe considerar que no caso que analisamos, se dão em função da ação deliberada - de origem pessoal ou institucional - movida por justificativas que, se a princípio se revestem de um discurso de transparência e moralidade, em muitos casos opacizam objetivos e interesses outros. Neste ponto, recuperamos a noção dos atos perlocutórios: são aqueles que, além de fazerem o que fazem, em sua condição de locução, produzem efeitos pelo fato de dizê-lo. Ou seja, são enunciações performativas que realizam pelo fato de enunciarem. Uma das hipóteses sobre a qual nos deteremos à frente instala-se nessa linha de raciocínio: que reais objetivos moveram o juiz responsável pela Operação Lava Jato para tomar a decisão tão rapidamente de quebrar o sigilo (a conversa entre Lula e Dilma teria se dado às $13 \mathrm{~h} 32$ e já no fim da tarde estava liberada para a imprensa e abastecendo em tempo real os portais jornalísticos, mas principalmente, em tempo hábil de ser noticiada pelos telejornais noturnos) das gravações, mesmo considerando que poderia estar quebrando prerrogativas do próprio Supremo Tribunal Federal?

\section{A performatividade dos vazamentos}

A ideia de vazamento de conversas, que seriam, até então presumidamente sigilosas, especialmente entre políticos, tem registros nada recentes na imprensa brasileira. De algum modo, o evidente avanço de recursos tecnológicos tem propiciado uma intensidade maior de interceptações e posterior divulgação desses diálogos pelos media jornalísticos, com a consequente vinda a público de trechos de conversas que acabam por impor-se, elas mesmas, como acontecimentos discursivos.

Presente no campo do jornalismo político, um exemplo do que aqui se denomina de performatividade do vazamento a ser citado é o caso que levou à demissão, em 1994, do então ministro da Fazenda, Rubens Ricupero. Enquanto se preparava para dar uma entrevista ao vivo ao jornalista Carlos Monforte, no Jornal da Globo, Ricupero conversava com o jornalista. O sinal da transmissão, no entanto, já estava aberto e parte do diálogo foi captado por centenas de antenas parabólicas que estavam na mesma frequência do sinal da Embratel. Foi quando o então ministro, ao referir-se ao seu apoio à candidatura de Fernando Henrique Cardoso à presidência da República, proferiu a frase que viria a the 
custar o cargo: "eu não tenho escrúpulos, o que é bom a gente fatura, o que é ruim a gente esconde".

Carvalho e Almeida (2012), ao analisar o caso sob a ótica da metáfora teatral, destacam que o jornalismo, neste caso percebido como ator social, "tem que se haver com outros atores sociais em um complexo jogo interativo e de negociações" (Carvalho e Almeida, 2012, p. 125). Para os autores, é imprescindível que se problematize, em situações como esta, aspectos como as formas de encenação, ou de performance, acionadas pelo jornalismo em sua interação com outros atores sociais.

Flagrados na região de fundo sugerindo uma falsa encenação, Carlos Monforte e Rubens Ricupero agrediram a plateia da sua encenação. Mas o que mais importa é que o gesto acabou por lançar dúvidas sobre a seriedade e os compromissos éticos e com o rigor de todo o jornalismo praticado pela Rede Globo, anteriormente já envolvida em outras situações que colocaram em xeque seus métodos jornalísticos (...) Decoro, polidez e compromisso ético com a plateia foram precisamente os elementos que se mostraram ausentes no Caso Ricupero (Carvalho e Almeida, 2012, p. 134).

O que distancia o vazamento da fala de Ricupero do caso em estudo neste artigo, para começar, é exatamente, isso - o fato de tratar-se, até onde se sabe, de um vazamento acidental. No caso do grampo do telefonema entre Lula e Dilma Rousseff, o que se percebeu foi uma ação deliberada e extremamente ágil do juiz Sérgio Moro em disponibilizar para a imprensa os áudios da conversa entre a presidenta e o ex-presidente.

Assim foi também com a divulgação, em 1999, de telefonemas que teriam sido ilegalmente grampeados pela Polícia Militar no Paraná contra associações de trabalhadores rurais ligadas ao Movimento dos Trabalhadores Sem Terra $(\mathrm{MST})^{2}$. O caso ganhou repercussão internacional e o Brasil foi condenado pela prática, dez anos depois, pela Corte Interamericana de Direitos Humanos da OEA (Organização dos Estados Americanos). Depois de quase dois

2 Em maio de 1999, o então major Waldir Copetti Neves, oficial da Polícia Militar do Paraná, solicitou à juíza Elisabeth Khater, da comarca de Loanda, no noroeste do estado, autorização para grampear linhas telefônicas de cooperativas de trabalhadores ligadas ao MST. A juíza autorizou a escuta imediatamente, sem qualquer fundamentação, sem notificar o Ministério Público e ignorando o fato de não competir à PM investigação criminal. Durante 49 dias os telefonemas foram gravados. Não havia embasamento legal para determinar a escuta. O que sugere a intenção de criminalizar os trabalhadores rurais grampeados. A Secretaria de Segurança Pública do Paraná convocou uma coletiva de imprensa e distribuiu trechos das gravações, que teriam sido editadas de maneira tendenciosa. O conteúdo insinuava que integrantes do MST planejavam um atentado à juíza Elisabeth Khater e ao fórum de Loanda. O material foi veiculado em diversos meios de imprensa, o que contribuiu para o processo de criminalização que o MST já vinha sofrendo. 
meses grampeando as ligações telefônicas de membros do MST paranaense, a Polícia Militar do Paraná, a quem não compete prevalentemente o ofício de investigação, convocou a imprensa e divulgou trechos dos áudios. Aquele era um momento de uma forte onda de tentativa de criminalização do MST e a notícia repercutiu em toda a grande imprensa brasileira. Em relação à suposta ilegalidade dos grampos telefônicos, ninguém nunca foi punido.

Tratamento muito diferente teve o banqueiro Daniel Dantas ${ }^{3}$, um nome que, desde os anos 1990 até a atualidade tem, de algum modo, se envolvido em denúncias, escândalos e com incidentes de vazamentos de gravações e documentos pela imprensa. Daniel Dantas, co-fundador do Banco Opportunity, depois se tornou um bilionário da pecuária. Protagonista de denúncias que envolveram milhões de dólares em casos que não exatamente foram esclarecidos, o nome do banqueiro nas últimas duas décadas aparece associado a escândalos e vazamentos de conversas por meio de grampos telefônicos, mas que, no seu caso, acabaram por garantir-lhe a absolvição.

Não seria exagero dizer que nos anos mais recentes o jornalismo passou a ter um status de protagonista nesses casos de vazamentos. Os media jornalísticos certamente não se restringem a uma condição de "divulgadores" dentro de um complexo jogo de forças que orquestram tais episódios para a busca do atingimento de objetivos específicos e imediatos. No caso em análise, vários detalhes chamam em especial a atenção: a decisão da Justiça Federal paranaense de divulgar uma conversa envolvendo a própria presidenta da República, a rapidez com que o juiz Sergio Moro despachou a liberação das gravações, os argumentos do juiz para fazê-lo e, por fim, o amplo espaço dado à notícia e o modo como a imprensa o cobriu.

Se, por assim dizer, a explosiva divulgação das conversas foi justificada pelo poder judiciário como forma de garantir a transparência e a democracia, outros sentidos devem ser aí percebidos. Por um lado, cumpriu a função de praticamente abortar a posse de Lula como ministro da Casa Civil, em momento de grande fragilidade institucional da presidência de Dilma Rousseff, sob a justificativa que isso Ihe daria foro especial. Por outro lado, e talvez o que deva

3 A referência aqui é à Operação Satiagaha da Polícia Federal (cujas investigações tiveram início em 2004 e levaram à prisão o banqueiro Daniel Dantas, em 2008), que apurou desvios de verbas públicas, corrupção e lavagem de dinheiro em ações de espionagem e sabotagem envolvendo a Brasil Telecom e a Telecom Itália. Houve, à época, a denúncia ações de investigação consideradas ilegais. O caso tornouse ainda mais conhecido pois reuniu uma sequência de vazamentos de informações e documentos. Curiosamente, houve, neste caso, pode-se assim afirmar, uma série de inversões de papéis em que investigadores se tornaram suspeitos e investigados e os investigados tornaram-se vítimas. Um caso emblemático também de como vazamentos sucessivos foram plantados e como os media jornalísticos são acionados com objetivos outros. 
ter atenção mais aprofundada, o fato de que toda esta situação agudizou ainda mais a crise política e de aceitação do governo Dilma Rousseff. Isolar o fato da divulgação pirotécnica das gravações somente contribui para uma opacização ainda maior dos acontecimentos que substanciaram a crise política do início de 2016. É necessário buscar compreendê-lo dentro de uma cadeia de discursos, atos e encenações que em muito contribuíram para criar as condições para o impeachment da presidenta Dilma. Cabe lembrar que o processo de cassação do mandato de Dilma Rousseff teve início em 2 de dezembro de 2015, quando o ex-presidente da Câmara dos Deputados Eduardo Cunha deu prosseguimento ao pedido dos juristas Hélio Bicudo, Miguel Reale Júnior e Janaína Paschoal. Com uma duração de 273 dias, o processo se encerrou em 31 de agosto de 2016, tendo como resultado o impeachment, mas sem a perda dos direitos políticos de Dilma.

\section{O grampo de Lula e Dilma}

A crise política detonada - na verdade, acentuada - com a divulgação das conversas telefônicas do ex-presidente Luiz Inácio Lula da Silva atingiu seu auge no dia 16 de março de 2016. Nesta data, o juiz federal Sergio Moro liberou para a imprensa conversas do ex-presidente que vinham sendo interceptadas desde o dia 19 de fevereiro de 2016, dentro da Operação Lava Jato, sob a justificativa de que o ex-presidente tentava atrapalhar o andamento de investigações, que envolviam o nome dele, de familiares do ex-presidente e de vários membros do Partido dos Trabalhadores, inclusive da própria presidenta Dilma Rousseff.

Tudo indica que a atenção sobre os telefonemas de Lula teria se intensificado depois de outra conversa interceptada entre o ex-presidente da República e o presidente do Partido dos Trabalhadores à época, Rui Falcão. Nesta ligação, ocorrida em 4 de março, no entendimento dos investigadores da Lava Jato, haveria fortes indícios de que Lula já se movimentava para prejudicar o curso das investigações. Fato que se agravou no dia 16 de março de 2016, quando foi interceptada pela Operação uma conversa entre Lula e Dilma Rousseff, que é sobre a qual este artigo se debruça especificamente.

Segundo os registros, a conversa entre Lula e Dilma teria ocorrido às 13h32. Neste momento, a presidenta Dilma, que já havia anunciado que o ex-presidente seria o novo ministro chefe da Casa Civil, ligou para o celular do motorista de Lula - que também estava sendo grampeado - e teve com o ex-presidente o seguinte diálogo, conforme foi amplamente divulgado pela imprensa já no fim da tarde daquele dia: 
Conversa Dilma-Lula

Dilma: "Alô."

Lula: "Alô."

Dilma: "Lula, deixa eu te falar uma coisa."

Lula:"Fala, querida. Ahn?"

Dilma: "Seguinte, eu tô mandando o Messias junto com o papel pra gente ter ele, e só usa em caso de necessidade, que é o termo de posse, tá?!"

Lula: "Uhum. Tá bom, tá bom."

Dilma: "Só isso, você espera aí que ele tá indo aí."

Lula: "Tá bom, eu tô aqui, fico aguardando."

Dilma: "Tá?!"

Lula: "Tá bom."

Dilma: "Tchau."

Lula:"Tchau, querida."

(Castro e outros, 2016).

A divulgação das gravações ao final da tarde do dia 16 de março, depois de o juiz Sergio Moro ter retirado o sigilo das interceptações telefônicas e que foram gravadas pela Polícia Federal, tiveram fortes impactos. No despacho em que liberou as gravações, Sergio Moro salientou que "pelo teor dos diálogos degravados, constata-se que o ex-Presidente já sabia ou pelo menos desconfiava de que estaria sendo interceptado pela Polícia Federal, comprometendo a espontaneidade e a credibilidade de diversos dos diálogos".(Moro citado por Leitão, 2016). Ainda no mesmo documento justificativo, Moro assinala que a quebra do sigilo das gravações teve os objetivos de propiciar a publicidade dos fatos e a ampla defesa dos envolvidos. $O$ juiz destaca ainda:

Como tenho decidido em todos os casos semelhantes da assim denominada Operação Lavajato, tratando o processo de apuração de possíveis crimes contra a Administração Pública, o interesse público e a previsão constitucional de publicidade dos processos (art. 5०, LX, e art. 93, IX, da Constituição Federal) impedem a imposição da continuidade de sigilo sobre autos. O levantamento propiciará assim não só o exercício da ampla defesa pelos investigados, mas também o saudável escrutínio público sobre a atuação da Administração Pública e da própria Justiça criminal. A democracia em uma sociedade livre exige que os governados saibam o que fazem os governantes, mesmo quando estes buscam agir protegidos pelas sombras (Moro citado por Leitão, 2016).

Retomamos aqui os pontos destacados de observação propostos para este artigo: a decisão da Justiça federal paranaense de divulgar uma conversa 
envolvendo a própria presidenta da República, a rapidez com que o juiz Sergio Moro despachou a liberação das gravações, os argumentos do juiz para fazê-lo e, por fim, o amplo espaço dado à notícia e o modo como a imprensa o cobriu. Em relação ao primeiro aspecto, o vazamento das gravações teve imediata reação de setores da política e de juristas. O governo Dilma reagiu imediatamente ao fato, salientando que a divulgação do conteúdo de telefonema entre a presidenta Dilma Rousseff e o ex-presidente Luiz Inácio Lula da Silva é uma "afronta" a direitos e garantias da Presidência da República. Segundo Matoso (2016), a Secretaria de Comunicação Social da Presidência da República informou que ocorreu «flagrante violação da lei e da Constituição da República, cometida pelo juiz autor do vazamento».

Já os juristas se dividiram: em entrevistas e artigos assinados em jornais e portais noticiosos, de um lado, o entendimento de que houve flagrante desrespeito à Constituição, haja vista que uma gravação de conversa envolvendo a presidenta da república só poderia se dar com a aprovação do Supremo Tribunal Federal (STF). Para outros juristas, no entanto, não se cometeu nenhuma ilegalidade, pois se o sigilo foi determinado pelo juiz Sergio Moro, ele mesmo poderia levantá-lo. O fato de a interceptação telefônica envolver a figura da presidenta da República acabou se colocando como um forte debate em paralelo pela imprensa e que se arrastou por semanas. Três meses depois, no entanto, o próprio STF entendeu que a ação do juiz foi inadequada. O juiz do STF, relator da Lava Jato na Corte, Teori Zavascki, destacou em despacho que Moro usurpou a competência do STF ao autorizar os grampos que gravaram a presidenta ${ }^{4}$.

O segundo aspecto a ser observado foi o estranhamento causado pela rapidez da decisão do juiz Sergio Moro em divulgar as gravações. A conversa telefônica entre Dilma e Lula ocorreu às 13h32. Durante a tarde, o juiz já havia decidido pela quebra do sigilo, feito o despacho e em pouquíssimo tempo as gravações já estavam nas mãos da imprensa, divulgadas em inserções extraordinárias e publicadas quase que em tempo real, praticamente simultâneo

4 Em 13 de Junho de 2016, o juiz Teori Zavascki, relator da Lava Jato no Supremo Tribunal Federal, determinou a remessa das investigações envolvendo o ex-presidente Lula para o juiz Sérgio Moro, responsável pela Lava Jato em primeira instância, em Curitiba. Na decisão, o ministro ainda anulou as escutas do ex-presidente em diálogo telefônico com Dilma Rousseff em março deste ano e apontou que Moro usurpou a competência do STF ao autorizar os grampos que gravaram a presidenta. Em seu despacho, Teori sustenta que "cabe apenas ao Supremo Tribunal Federal, e não a qualquer outro juízo, decidir sobre a cisão de investigações envolvendo autoridade com prerrogativa de foro na Corte". Para o ministro, "a violação da competência do Supremo Tribunal se deu no mesmo momento em que o juízo reclamado, ao se deparar com possível envolvimento de autoridade detentora de foro na prática de crime, deixou de encaminhar a este Supremo Tribunal Federal o procedimento investigatório para análise do conteúdo interceptado. E, o que é ainda mais grave, procedeu a juízo de valor sobre referências e condutas de ocupantes de cargos". (Zavascki, 2016, p. 8). 
à sua liberação pela Polícia Federal, nos portais noticiosos. Impossível não considerar que parece ter havido aí uma forte preocupação com o timing dos telejornais noturnos e sua enorme audiência para que a notícia estivesse nas edições ainda daquele 16 de março, uma quarta-feira. Ainda nesse mesmo sentido, a agilidade da quebra do sigilo parece ter tido outros objetivos: por um lado, impactar a opinião pública (e, ao que parece, com certo sucesso, haja vista que houve protestos em muitas capitais e grandes cidades pelo País) e, por outro, mesmo tentar constranger a posse de Lula como ministro, nomeação que havia sido divulgada pelo Palácio do Planalto na manhã daquele mesmo dia. Se assim foi, cumpriu seu objetivo ${ }^{5}$.Tais aspectos denotam, de algum modo, o complexo jogo entre ação feita discurso e discurso feito ação acionados de modo intervencionista em termos da realidade política e social e o desejo de controlar o curso dos acontecimentos.

E algumas das manchetes dos jornais e portais noticiosos parecem confirmar tal perspectiva.

"Moro derruba sigilo e divulga grampo de ligação entre Lula e Dilma" (G1, em 16/03/2016);

"Grampo indica que Lula queria atuação de Dilma em favor dele no STF" (Folha, em 16/03/2016);

"OAB nacional lamenta teor de conversas gravadas e seccionais criticam vazamento" (ebc.com.br, em 17/03/2016);

"Duas visões: juristas divergem quanto a gravação de conversa entre Lula e Dilma" (bbc.com, em 17/03/2017);

"Protestos e panelaços tomam cidades pelo Brasil após grampo" (exame.abril.com, em 16/03/2106);

"Grampo de conversa entre Dilma e Lula é 'típica de Estados policiais', diz OAB-RJ (brasil.gov.br, em 30/03/2016).

Atendo-nos ainda à performatividade dos vazamentos no ambiente mediático não se pode desconsiderar que a chegada desses materiais (em geral, audiovisuais) à imprensa tem um caminho nem sempre tão claro em termos de sua origem e, em especial, de seu patrocínio, que ajudaria certamente a melhor compreender as intencionalidades de tal divulgação - mais ainda, como já aludido neste artigo, de que conjuração de interesses resulta a decisão de fazer com que cheguem rapidamente a público.

5 Em 18 de Março de 2016, dia seguinte à posse de Lula como ministro chefe da Casa Civil, o ministro Gilmar Mendes, do Supremo Tribunal Federal, suspendeu a nomeação do ex-presidente. A decisão foi proferida em ação apresentada pelo PSDB e pelo PPS. Na decisão, o ministro afirma ter visto intenção de Lula em fraudar as investigações sobre ele na Operação Lava Jato. O petista ainda pode recorrer da decisão ao plenário do Supremo. 
Temos, no entanto, uma pista elucidativa quando nos referenciamos na prática do juiz Sérgio Moro, considerado pela própria imprensa como o ícone maior de uma controversa modalidade de aplicação legal que se tornou recorrente na prática dos vazamentos. Este juiz escreveu um artigo, antes de se tornar o responsável, na Justiça Federal do Paraná, pelas ações da chamada Operação Lava Jato, no qual defende a utilização dos media como estratégia para alcançar objetivos jurídicos pela pressão a partir da opinião pública. No artigo, intitulado Considerações sobre a operação mani pulite, que investigou políticos e empresários italianos, Moro afirma:

\begin{abstract}
Talvez a lição mais importante de todo o episódio [operação mani pulite] seja a de que a ação judicial contra a corrupção só se mostra eficaz com o apoio da democracia. É esta quem define os limites e as possibilidades da ação judicial. Enquanto ela contar com o apoio da opinião pública, tem condições de avançar e apresentar bons resultados. Se isso não ocorrer, dificilmente encontrará êxito. Por certo, a opinião pública favorável também demanda que a ação judicial alcance bons resultados. Somente investigações e ações exitosas podem angariá-la. Daí também o risco de divulgação prematura de informações acerca de investigações criminais. Caso as suspeitas não se confirmem, a credibilidade do órgão judicial pode ser abalada (Moro, 2004, p. 61).
\end{abstract}

Considerações premonitórias, a indicar o futuro da própria Operação Lava Jato e do juiz por ela responsável no Paraná, cinismo, mudança radical de postura? Tudo isso junto, talvez, a indicar que ações como os vazamentos, legitimadas e adotadas por Sergio Moro, representam a falácia do controle dos acontecimentos. Mais ainda: a sensação de que em termos da região de fundo, as motivações seriam tantas outras para além do trabalho de ofício de um representante da Lei, preocupado com a "credibilidade do órgão judicial".

\title{
Considerações outras
}

Duas dimensões de problemas estiveram presentes no percurso desse artigo: o que se altera no estatuto ontológico, teórico e metodológico dos acontecimentos quando, na perspectiva de Pierre Nora (1984), eles não podem modernamente existir sem a presença dos media; e o que significa, para os próprios media, particularmente os jornalísticos, a"validação"deacontecimentos controversos como os vazamentos que aqui abordamos. A primeira dimensão, como buscamos salientar, implica cuidado em não tomar como pacífica a compreensão dos acontecimentossegundoaslógicas narrativase discursivasque Ihe são propostas por seus detonadores. Em outros termos, os acontecimentos, como lembram teóricos situados em variadas tradições analíticas, uma vez 
eclodidos, não podem ser controlados em seus desdobramentos, pois estão sujeitos agora à dialética agir-sofrer o acontecimento, que implica, como salientamos, jogos de poder e disputas de sentidos. Ações discursivas e discursos tornados ações são freneticamente acionados na tentativa de deter os transbordamentos provocados pelos acontecimentos, o que requer uma sequência de novos acontecimentos, em analogia quase perfeita com a bola de neve que rola despenhadeiro abaixo, incontrolável.

A divulgação da interceptação telefônica entre a presidenta Dilma Rousseff e o ex-presidente Lula, para que tivesse efeito prático, teve que contar, primeiro, com um ambiente político de desgaste da presidência e do Partido dos Trabalhadores junto a setores da opinião pública, naquele momento, majoritários. A ideia generalizada de combate à corrupção, que ajudou a sedimentar tais sentimentos de reprovação, não pode também ser desprezada. Mas sem outras ações, como a suspensão, pelo ministro do Supremo Tribunal Federal, Gilmar Mendes, da posse do ex-presidente Lula como ministro da Casa Civil, aquele vazamento da conversa poderia se constituir como um acontecimento a mais na rotina de vazamentos de telefonemas, documentos e tantas outras informações que se tornou corriqueira no período que antecedeu e se sucedeu ao controverso processo que resultou no impeachment da presidenta Dilma Rousseff. A própria controvérsia em torno da legalidade da captação das conversas e da sua divulgação é sintomática do quanto há de violência na tentativa de forjar acontecimentos que moldem o curso histórico de uma sociedade. Mas também, quando cotejamos com os vazamentos contra movimentos sociais como o MST e os que atingiram Daniel Dantas, o quanto alguns atores policiais, do judiciário e do Ministério Público se mostram deletérios para a imagem da justiça e da polícia como aplicável sem distinções por condições econômicas, ideológicas, políticas, comportamentais ou outras variáveis.

A segunda dimensão do problema dos acontecimentos em sua íntima e dependente relação com os media está em quanto ela pode ser danosa eticamente ao jornalismo, quando perspectivada prevalentemente em função das relações de poder, seja de que natureza for. Se a credibilidade é o valor maior de que se valem os media noticiosos, ela está assentada historicamente em supostas ações de independência face às forças políticas, econômicas, culturais, ideológicas, comportamentais e outras variáveis da vida social. Boa parcela dos media brasileiros se mostrou tão comprometida com princípios políticos, econômicos, culturais, comportamentais e ideológicos quanto os promotores dos vazamentos como acontecimentos visando fins específicos. Se, por um lado, há um dado negativo para os próprios media, que têm revelada sua verdadeira essencialidade, distante de pressupostos éticos e da equidade 
no trato informativo dos acontecimentos, por outro tem como dado positivo para a sociedade esse mesmo desmascaramento, trazendo à tona falácias historicamente repetidas à exaustão. Vale aqui recorrer à máxima segundo a qual as democracias não poderiam existir sem a imprensa, mas pensar como, por outro lado, em determinadas circunstâncias, é a própria democracia que pode não resistir a certa modalidade de imprensa.

Refletindo sobre o futuro da imprensa escrita após o crescente interesse e difusão de outras modalidades de produção e consumo de informação, o professor Robert G. Picard, em artigo intitulado Contemplating Democracy without the Press (Contemplando a democracia sem a imprensa, em tradução livre), afirma:

A maioria de nós assumiu que a democracia requer a imprensa como a conhecemos. Teóricos democráticos e sociais, de John Milton a Thomas Jefferson, de Alexis de Tocqueville a John Dewey e de Walter Lippmann a Jürgen Habermas, todos afirmaram os papéis da imprensa na criação de uma comunidade política e retrataram a imprensa como intermediária entre governadores e governados, como superintendentes de atos governamentais e como criadores de fóruns em que o debate público ocorre. Na prática, no entanto, essas relações nunca foram tão evidentes porque a democracia se desenvolveu e prosperou antes que a imprensa, tal como a conhecemos hoje, existisse. Mesmo em tempos modernos, movimentos democráticos para derrubar o colonialismo e suas condições residuais foram bem sucedidos sem uma imprensa democraticamente inclinada ou simpatizante. Na África e Ásia surgiram democracias quando as condições e poderes coloniais, como o apartheid, foram rejeitados pela população, apesar da falta de apoio na imprensa. A luta pela democracia na Europa Central e Oriental avançou sem a imprensa realizando as funções democráticas que acreditamos que elas servem ${ }^{6}$ (Picard, 2009, p. 70. tradução nossa).

6 Most of us have assumed that democracy requires the press as we know it. Democratic and social theorists from John Milton and Thomas Jefferson, Alexis de Tocqueville to John Dewey, and Walter Lippmann to Jürgen Habermas have all asserted the roles of the press in creating political community and have portrayed the press as intermediaries between governors and the governed, as overseers of governmental acts, and as creators of forums in which public debate takes place. In practice, however, these relations have never been so evident because democracy developed and thrived before the press as we know it today even existed. Even in modern times, democratic movements to overthrow colonialism and its residual conditions were successful without a democratically leaning or sympathetic press. In Africa and Asia, democracies emerged when colonial powers and conditions such as apartheid were rejected by the population despite the lack of support in the press. The struggle for democracy in Central and Eastern Europe went forward without the press carrying out the democratic functions we believe they serve. (Picard, 2009, p. 70). 
Mais do que uma referência restrita à forma impressa do jornalismo (a imprensa), Robert G. Picard nos permite vislumbrar um modelo de produção noticiosa que se alastrou para os media eletrônicos tradicionais, como rádio e televisão, e mesmo para a internet. Importa mais para os nossos propósitos, no entanto, a reflexão sobre a tênue relação entrejornalismo, democracia e cidadania que episódios como os vazamentos transformados em acontecimentos nos permite perscrutar e que aqui abordamos em algumas de suas possibilidades.

Agradecimentos: A produção desse artigo foi possível, em parte, pelo financiamento de pesquisas por parte do CNPq e da Fapemig.

\section{Referências}

CARVALHO, Carlos Alberto; ALMEIDA, Fábio Augusto Seletti. A coxia sobe ao palco: notas sobre o jornalismo como atos social a partir do Caso Ricupero. In: CARVALHO, Carlos Alberto; BRUCK, Mozahir Salomão. Jornalismo: cenários e encenações. São Paulo: Intermeios, 2012.

CASTRO, Fernando; NUNES, Samuel; NETTO, Vladimir. Moro derruba sigilo e divulga grampo de ligação entre Lula e Dilma; ouça. G1 PR e TV Globo, Paraná, 17 mar. 2016. Disponível em: http://g1.globo.com/pr/parana/noticia/2016/03/pflibera-documento-que-mostra-ligacao-entre-lula-e-dilma.html. Acesso em: 4 jan. 2018.

FERREIRA, Flávio. Grampo indica que Lula queria atuação de Dilma em favor dele. Folha de S. Paulo. Disponível em: https://www1.folha.uol.com.br/ poder/2016/03/1750772-grampo-indica-que-lula-queria-atuacao-de-dilmaem-favor-dele-no-stf.shtml. Acesso em: 4 jan. 2018.

LEITÃO, Matheus. Lula sabia ou desconfiava que estaria sendo interceptado, diz Moro. G1: Blog do Matheus Leitão, 16 mar. 2016. Disponível em: http://g1.globo.com/ politica/blog/matheus-leitao/post/lula-sabia-ou-desconfiava-que-estariasendo-interceptado-diz-moro.html. Acesso em: 4 jan. 2018.

MARTINS, Raphael. Protestos e panelaços tomam cidades pelo Brasil após grampo. Exame. Disponível em: https://exame.abril.com.br/brasil/protestos-tomamporta-do-planalto-veja-repercussao/. Acesso em: 4 jan. 2018.

MATOSO, Filipe. Planalto diz que Moro violou a lei ao divulgar telefonema entre Lula e Dilma. G1: Política, 16 mar. 2016. Disponível em: http://g1.globo.com/politica/ noticia/2016/03/planalto-ve-afronta-direito-de-dilma-em-divulgacao-detelefonema.html. Acesso em: 3 jan. 2018. 
MORO, Sergio Fernando. Considerações sobre a operação mani pulite. Revista CEJ - Justiça Federal. Brasília, n. 26, p. 56-62, jul./set. 2004. Disponível em: http:// media.folha.uol.com.br/poder/2015/12/29/trabalho_internet_revista.pdf. Acesso em: 4 jan. 2018.

MOUILLAUD, Maurice; PORTO, Sérgio Dayrell (org.). $\mathbf{O}$ jornal da forma ao sentido. Brasília: Paralelo 15, 1997.

NORA, Pierre. Entre memória e história: a problemática dos lugares. Projeto História, v. 10, dez. 1993. Disponível em: https://revistas.pucsp.br/index.php/revph/ article/viewFile/12101/8763. Acesso em: 20 dez. 2017.

. O acontecimento e o historiador do presente. In: NORA, Pierre e outros. A nova história. Lisboa: Edições 70, 1984.

PICARD, Robert G. Contemplating Democracy without the Press. Annual Report 2009 STIFTELSEN TINIUS. Disponível em: https://www.academia.edu/31045811/ Contemplating_Democracy_without_the_PressAcesso em: 2 jan. 2018.

PORTAL BRASIL. Grampo de conversa entre Dilma e Lula é 'típica de Estados policiais', diz OAB-RJ. Governo do Brasil. Disponível em: http://www.brasil.gov.br/ cidadania-e-justica/2016/03/grampo-de-conversa-entre-dilma-e-lula-e2018tipica-de-estados-policiais2019-diz-oab-rj. Acesso em: 4 jan. 2018.

PUFF, Jefferson. Duas visões: juristas divergem quanto a gravação de conversa entre Lula e Dilma. BBC Brasil. Disponível em: https://www.bbc.com/portuguese/ noticias/2016/03/160317_juristas_grampos_jp. Acesso em: 4 jan. 2018.

QUÉRÉ, Louis. A dupla vida do acontecimento: por uma realidade pragmatista. In: Acontecimento: reverberações. FRANÇA, Vera Regina Veiga; OLIVEIRA, Luciana (orgs.). Belo Horizonte: Autêntica Editora, 2012.

RODRIGUES, Adriano Duarte. O acontecimento. In: TRAQUINA, Nelson. Jornalismo: questões, teorias e "estórias". Lisboa: Vega, 1993.

RODRIGUES, Alex. OAB nacional lamenta teor de conversas gravadas e seccionais criticam vazamento. EBC. Disponível em: http://agenciabrasil.ebc.com.br/ politica/noticia/2016-03/oab-nacional-lamenta-teor-de-conversas-gravadase-seccionais-criticam. Acesso em: 4 jan. 2018.

RICOEUR, Paul. Tempo e narrativa - Tomo I. Campinas: Papirus, 1994.

TUCHMAN, Gaye. Making News: a Study in the Construction of Reality. New York: Free Press, 1978.

VICENTE, Maximiliano Martin. História e comunicação na ordem internacional. São Paulo: Editora UNESP; São Paulo: Cultura Acadêmica, ISBN 978-85-98605-96-8, 2009. 
ZAVASCKI, Teori. Reclamação 23.457. Brasília: 13 jun. 2016. Disponível em: http:// politica.estadao.com.br/blogs/fausto-macedo/wp-content/uploads/ sites/41/2016/06/TEORILULA.pdf. Acesso em: 27 dez. 2017.

Recebido em: 16/01/2018

Aceito em: 04/05/2018

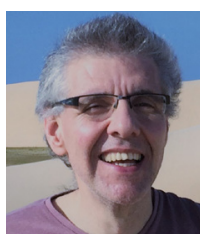

Dados dos autores:

Carlos Alberto Carvalho | carloscarvalho0209@gmail.com

Universidade Federal de Minas Gerais

Pós-Doutor pela Universidade do Minho, Portugal, e Doutor em Comunicação pela UFMG. Professor

adjunto do Programa de Pós-Graduação em Comunicação Social da Universidade Federal de Minas Gerais (PPGCOM-UFMG).

Endereço do autor:

Faculdade de Filosofia e Ciências Humanas - Secretaria do Programa de Pós-Graduação em Comunicação (PPGCOM-UFMG)

Av. Antônio Carlos, 6627 - $4^{\circ}$ Andar - Sala 4234

Campus Pampulha

31.270-901 - Belo Horizonte/MG

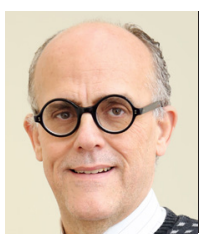

Mozahir Salomão Bruck | mozahir@uol.com.br

Universidade Católica de Minas Gerais

Pós-Doutor pela Universidade Fernando Pessoa em Porto, Portugal, Doutor em Literaturas de Língua Portuguesa pela PUC Minas e Mestre em Comunicação pela UFRJ. Coordenador e professor adjunto IV na Graduação em Jornalismo e no Programa de Pós-Graduação em Comunicação Social da Pontifícia Universidade Católica de Minas Gerais (PPGCOM-PUC Minas).

Endereço do autor:

Programa de Pós-Graduação em Comunicação Social da Pontifícia Universidade Católica de Minas Gerais (PPGCOM-PUC Minas)

Av. Trinta e Um de Março, 1020 - Prédio 93

Bairro Dom Cabral

30.535-000 - Belo Horizonte/MG

Contribuições dos autores: Ambos os autores fizeram contribuições substanciais para concepção, desenvolvimento, redação e revisão crítica do trabalho; e aprovação final da versão para publicação. 